\title{
S' o riso tocasse meu coração
}

\author{
FERNANDO LIRA XIMENES
}

Doutor em Artes Cênicas pela UFBA (2008), Professor do Curso de Licenciatura em Teatro do IFCE, Coordenador do Grupo Pesquisa CRISE do IFCE (Comicidade, Riso e Experimentos); dirigiu os espetáculos "E pensar que tudo isto é oco!!" (2005), "Para Não Falar de Teatro" (2008), "Terra Grávida" (2006), "O Pagador de Promessas" (2010), "Qual é o Final?" (2012), todos realizados no estado do Ceará. 


\section{- RESUMO}

Este artigo, que está mais para um ensaio de um ensaio, poderia chamar-se: "Quatro propostas para uma próxima gargalhada". Assim, como nas seis propostas de Italo Calvino que eram cinco em vez de seis, aqui temos apenas três. No entanto, todas as três propostas, na essência, têm o mesmo objetivo: identificar possibilidades de alcançar o risível, através da imaginação e da experiência que possuem a capacidade de nos tocar. Não há aqui a pretensão de apresentar fórmulas. Racionalizar sobre a causa do riso é de fato uma atividade inglória. É como se quiséssemos explicar a piada, perde-se a graça! Deseja-se apenas apontar pistas para um olhar que, às vezes, parece em gestação, mas ainda não reparou que nascera deveras.

- PALAVRAS-ChAVE: Comicidade, riso, imaginação.

\section{- ABSTRACT}

This paper, which is more like an essay to an essay, could be called: four proposals for a next laugh. Thus, as in the six proposals of Italo Calvino which were five instead of six, here we have only three. However, all them, in essence, have the same objective: to identify opportunities to achieve the laughable, through imagination and experience that have the ability to touch us. There's not the pretension to present rules. Rationalize about the cause of laughter is indeed an inglorious activity. As if we wanted to explain the joke, you lose the grace! The wish is just to point out clues for a look that sometimes seems in gestation, but haven't noticed that indeed was born.

\section{KEYWORDS}

Humour, laughter, imagination.

\section{A ordem dos tratores (não) altera o viaduto...}

O risível como objeto de comunicação é probabilístico. Um autor de comédia não tem a mínima certeza de que sua criação obterá da plateia a recepção desejada antes da encenação. Há algo de misterioso na história, na memória dos envolvidos, no estado psicológico e físico, ou em outros fatores do imaginário, que lhes dão a predisposição para o riso. A única garantia que o autor possui é sua própria concepção e experiência do que seja risível, baseada exclusivamente em observações e sentimentos empíricos.

No seu ensaio "O riso: ensaio sobre a significação da comicidade", Henri Bergson usa como fio condutor de suas teorias para as causas e a produção do riso a metáfora do Mecânico Colado no Vivo. Nessa abordagem, será risível tudo aquilo que, na vida social, se relacione com o humano, nos parecendo rígido, autômato, lembrando-nos funcionamentos mecânicos. Encontramos essas imagens na moda, nas regras dos rituais sociais, na produção acadêmica, nas posturas rígidas de algumas profissões como de professores, advogados, padres, médicos, políticos, militares, etc.

Não existe uma única causa para o riso, ou causa primeira do riso, mas várias causas. Assim, como Bergson, muitos tentaram uma explicação do risível com argumentos bem sistematizados, baseados em exemplos, mas falharam ao depararem com contraexemplos. Cabe ao artista não mais se fechar em fórmulas, porém, antes de tudo, escolher caminhos possíveis que permitam atingir os efeitos desejados.

E um dos caminhos é a desordem! 
O riso é inimigo da ordem! Na inversão do mundo sensível, o riso renova uma experiência de emoções que a realidade séria não dá conta. A experiência pelo risível é também a experiência de uma verdade. Não a verdade absoluta, mas a apreensão de um conhecimento do sentido do que somos e ao que nos acontece, no qual, muitas vezes, a razão séria nem de leve consegue tocar.

No texto Jorge Larrosa, "Notas sobre a experiência e o saber da experiência", nos fala que a experiência é "o que nos passa, o que nos acontece e o que nos toca" (BONDÍA, 2001, p. 2). Como, então, posso pensar na experiência do risível, na visão de Bergson, quando este afirma que o riso acontece na medida em que há uma certa anestesia do coração? É possível, pensando desse modo, que o riso seja uma experiência que nos toca?

Ora, se me acontece rir de alguma coisa, é porque fui de certa forma tocado por algo que me impulsionou a uma reação física. Mesmo que não aconteça uma reflexão imediata do que significa em mim o sentido do meu riso, com certeza algo me afetou. Assim sendo, o objeto que nos faz rir nos toca, do contrário, não provocaria o seu efeito.

No entanto, o que nos toca, o que nos dá um sabor de experiência, não é um sentido inteligível, mas uma sensação misteriosa que se esconde nas memórias contidas em nosso corpo. A experiência do risível nem sempre é a experiência da razão. Para o riso, é muito forte a ideia de que "pensar não é somente "raciocinar" ou "calcular" ou "argumentar", como nos tem sido ensinado algumas vezes, mas é sobretudo dar sentido ao que somos e ao que nos acontece" (BONDÍA, 2001, p. 2). É, portanto, na incongruência, no estranhamento, no absurdo, na irrealidade, que, algumas vezes, o efeito do riso é mais forte.

E qual a imagem do riso que nos toca?

Para Bergson, o riso acontece quando temos a impressão de que vida se desviou no sentido de uma mecânica. A vida, para o filósofo francês, caminha sempre em frente diferenciando-se em qualidade e quantidade, sempre obedecendo a certas flexibilidades, não havendo repetições nem inversões, muito menos sobreposições de situações. A experiência vivida não é repetível, não é documentada, nem transmitida. A experiência da vida acontece no seu momento presente. Já o riso, para Bergson, se dá, portanto, quando a vida apresenta-se como um mecanismo que se repete, que se inverte e que se interpõe como peças de uma engrenagem. Pelo estranhamento entre o que a vida deveria ser e o que ela é de fato, é que rimos. Isso não significa que haja uma reflexão comparativa - em alguns casos pode até haver -, mas, sim, a percepção de que algo na nossa noção que temos de congruência foi afetada.

A experiência do riso, ou melhor dizendo, a experiência de quem ri, obedece a caminhos imprevistos, não tem uma meta, é repentina e prima pelos desvios da vida e suas surpresas. Por isso, a experiência através do risível é reveladora, abre as portas, nos liberta da alienação, nos cativa, nos toca o coração pelo prazer. A experiência do riso nos leva a territórios de passagem que requerem uma certa passividade, uma receptividade e disponibilidade para abertura de caminhos labirínticos. A experiência do riso tem uma qualidade existencial que a vida cotidiana não consegue alcançar.

$O$ ator cômico é um deformador de imagens por excelência. Ele tem a habilidade de nos libertar das imagens primeiras e, como num truque de mágica, nos desloca para outras imagens, diferentemente da percepção anterior. Ele revela a ilusão das imagens. Como se utilizasse um espelho, ele vira de ponta cabeça a realidade 
e nos convida à viagem ao mundo paralelo das imagens in(di)vertidas. Mundo este que se apresenta móvel, fluido e onírico, talvez.

Para a produção do riso, a deformação da imagem tem valor capital. A imagem pode ser construída a partir de lembranças e pode ser induzida a partir de sugestões. Ela busca, antes de tudo, uma construção de um falso sentido. Procura estabelecer uma relação causal predeterminada entre as ações. Assim, a deformação da imagem cômica é produzida quando nos faz acreditar que os caminhos pelos quais as ações estão nos levando são o que preconcebemos. O riso que nos acorda do sonho, acontece justamente quando percebemos que fomos levados para um caminho imprevisto, quebrando, assim, a lógica dos sentidos esperados, ou desejados.

O imaginar, ou o estado imaginativo, também é uma experiência vivida. Do mesmo modo que, quando sonhamos, estamos vivenciando uma experiência. Na comédia, há esse convite para a imaginação e para o sonho, e o momento do riso é o despertar do sonho. É o momento em que o espectador se dá conta de que foi ludibriado, que tem uma relação próxima com a ilusão. Mas, ao contrário da raiva, há prazer, pois ele sabe que a ilusão faz parte do jogo. O comediógrafo faz com que a imaginação pareça a realidade. Ele pretende que o espectador adormeça e sonhe que está acordado, e o riso acontece quando ele acorda e percebe que estava dormindo.

A comédia quase sempre se estrutura de modo que a imaginação do espectador possa abandonar o curso ordinário das coisas. Uma imaginação que possa se ausentar e lançar a uma nova vida, produzindo viagens imaginárias e infinitas por itinerários não muito regulares. A comédia eleva, suspende o espectador em seu sono e, ao fazê-lo cair, acorda-o pelo riso.

A imaginação cômica é como um guia cego. Ela é também a imagem dos estados alterados na consciência, do jogo e da loucura. Mas, a imaginação cômica não é inconsequente em sua essência, embora seja irreverente em suas ações. Ela revela o não dito, o invisível, o subentendido. A imagem cômica é ambivalente. Ao mesmo tempo que castiga, ela absorve; ao mesmo tempo que rebaixa, ela eleva, e, ao mesmo tempo que cala, ela fala. A imagem cômica não é contraditória, mas nos revela a contradição.

\section{Com quantas piadas se dá uma risada...}

Para Bergson, o riso das situações cômicas é um reflexo das sensações que tivemos na infância, quando nos divertíamos com os brinquedos infantis: "não pode haver ruptura entre o prazer de brincar, na criança, e o mesmo prazer, no adulto" (BERGSON, 1983, p. 42). Nesse aspecto, Bergson se baseia na teoria freudiana dos recalques da infância refletidos na vida adulta: "nada é tão difícil para o homem que abdicar de um prazer que já experimentou" (FREUD, 1992, p. 422).

Ao brincar, a criança leva a sério. Isso não implica que não se divirta, não se descontraia, não ria. Ela está sempre ligando essas brincadeiras a objetos tangíveis, à realidade. No entanto, na fase adulta, a pessoa abandona os brinquedos de sua atividade social. Do adulto, espera-se que não brinque, pois isso quebra a lógica da vida; é uma inversão dos desejos na evolução do tempo. O adulto é recriminado por ser infantil. Seu tempo de brincadeira já passou. A realidade é outra. A realidade da vida adulta é a da seriedade, da rigidez, dissociada das brincadeiras infantis. É vergonhoso, portanto, comportar-se infantilmente quando se é adulto, foge às regras sociais e da natureza. Segundo Freud, 
"as forças motivadoras das fantasias são os desejos insatisfeitos, e toda fantasia é a realização de um desejo, uma correção da realidade insatisfatória" (FREUD, 1992, p. 422). Desse modo, o passado, o presente e o futuro estão entrelaçados pelo fio do desejo e, ao rirmos, estamos tentando reprimir esse desejo.

Bergson associa a lembrança que nos remete a maioria das situações cômicas a imagens do mecanismo de funcionamento de três brinquedos infantis: o boneco de mola, a marionete e a bola de neve.

O boneco de mola - A ideia que abstraímos do mecanismo desse brinquedo é a da oposição à ação de distensão e compressão. A mola representa a rigidez, a inflexibilidade, a resistência às mudanças. É, também, o esforço reprimido entre o desejo e a consciência moral; o conflito entre duas obstinações antagônicas que nos parecem mecânicas. São situações cômicas, como boneco de molas, aquelas que acontecem repetidas vezes, contrárias, insistentes intenções de uma ou mais personagens. É a rigidez elevada ao extremo, oscilando entre a vontade e a repressão, que torna risível essa imagem mecânica da vida.

A marionete - Esse brinquedo nos dá a imagem de um boneco que tem todas as suas articulações presas por cordas e seus movimentos estão controlados por um manipulador que determina as ações do boneco. É, pois, a ideia de se estar dominado, ou conduzido, como um joguete na mão de outros, que estabelece as situações cômicas. A farsa, a trapaça, fazer o outro de bobo, são algumas das características representadas nos mecanismos das marionetes. O cordão, que parece nos limitar, prende-nos aos devires e tolhe a transformação natural do mundo. Todos esses sentimentos vitais são traduzidos em comédia, quando mostramos que a liberdade nas pessoas é aparente. Todos somos conduzidos por nossas paixões e sonhos, cujos cordões estão nas mãos da necessidade, e que nos prende como grilhões invisíveis. A representação exagerada dos desejos mais recônditos da alma torna visíveis tais cordões, provocando o riso.

A bola de neve - Esse caso representa a ideia da reação em cadeia, do efeito dominó. Pequenos incidentes geram novos, sempre crescentes em intensidade, com consequências muitas vezes desastrosas. As comédias de O Gordo e O Magro, por exemplo, estão recheadas de situações cômicas que, a partir de coisas simples e banais, complicam-se e se avolumam como uma bola de neve descendo montanha abaixo. Nessa imagem, a vida parece se diferenciar em intensidade e grau, o que caracteriza o aspecto mecânico das ações. O riso se estabelece pelo desvio do curso natural da vida, a qual. por sua vez, é comparada a um brinquedo que parece se expandir, evoluir no espaço e no tempo, até que o estranhamento da situação provoque uma explosão de risos.

O efeito cômico tem seu tempo, sua duração, por isso ele exige que a percepção seja instantânea, que o estranhamento se realize de forma imediata, para que nem a inteligência nem a elaboração formal atrapalhem a reação prevista. Deve haver, portanto, um distanciamento, uma imparcialidade de quem observa uma situação cômica, para que seu efeito aconteça.

Se pudermos estar atentos à vida em sua evolução no tempo, perceberemos que tudo caminha para frente, no devir contínuo, rumo ao futuro, sem repetições, sem voltas, sem retorno. Cada instante de nossas vidas é único. 
O desvio da vida, portanto, é o que nos causa o estranhamento, no que ela tem de mecânica, automática, repetida, invertida e simultânea, dando-nos a ideia de brinquedo. É pela lembrança do passado, atualizada no presente, que as brincadeiras infantis suscitam as mesmas sensações agradáveis, manifestadas pelo corpo, através do riso.

\section{O que os olhos não veem, o coração (res)sente...}

Sei ter o pasmo essencial Que tem uma criança se, ao nascer, Reparasse que nascera deveras...

Fernando Pessoa

Gostaria de encerrar, falando de uma experiência que marcou a minha infância e parte da adolescência. Trata-se da leitura de um certo livro que foi "moda" em uma época. Veja se dá para adivinhar: essa obra, muitas vezes, foi jocosamente referida como o livro das misses. É isso mesmo: O Pequeno Príncipe, não o de Maquiavel, mas de Antoine de Saint-Exupéry'! Não ria! Essa é de fato uma injustiça preconceituosa tanto para com as misses, como para a obra e o seu autor.

Um dia, na infância, minha mãe compra um disco (na época, de vinil) que narra a história de um aviador com pane em seu avião, no deserto do Saara, quando, sem explicação, surge uma criança a lhe fazer uma porção de perguntas, mas não responde a nenhuma.

$\mathrm{Na}$ época, eu não compreendia muito bem a história, embora viajasse em imagens de pequenos planetas, de acendedores de lampião, rosas, raposas, serpentes e estrelas. Com o tempo, e de tanto repetir o disco, três imagens passaram a inquietar a minha curiosidade. A primeira era a do desenho que o aviador fizera quando criança, o qual todos os adultos achavam que era um chapéu. No entanto, foi apenas outra criança que conseguiu perceber no desenho uma jiboia com um elefante dentro. A segunda imagem era de outro desenho. O principezinho solicita ao aviador que lhe desenhe um carneiro. $O$ aviador faz vários que o Príncipe recusa, alegando que o carneiro é magro, ou que não é carneiro, mas um bode. Por fim, o aviador, estando muito ocupado consertando o avião, às pressas, rabisca uma caixa, faz um furo em cada lado e diz: Esta é a caixa, o carneiro encontra-se dentro! E o Príncipe: Era justamente o que queria!

E, por último, quando o Príncipe está prestes a "partir", oferece ao aviador, como presente, estrelas que sabem rir, dizendo:

Quando olhares o céu de noite, porque habitarei uma delas, porque numa delas estarei rindo, então será como se todas as estrelas te rissem, e tu terás estrelas que sabem rir (SAINT-EXUPÈRY, 1994, p. 87).

Foi somente na adolescência que essas três imagens passaram a ter um significado profundo para mim, a ponto de terem influenciado minha visão de mundo e, de

\footnotetext{
Saint-Exupéry era capitão e piloto de aviões. Fazia reconhecimentos aéreos e morreu em sua última missão em 1944, aos quarenta e quatro anos de idade. Como que por ironia, caiu em algum lugar do deserto e seu corpo nunca foi encontrado. Talvez, o principezinho viera e o levara para seu pequeno planeta.
} 
certo modo, o meu fazer artístico. Desde então, compreendi que O Pequeno Príncipe não era uma simples narrativa, uma historinha infantil boba, subliteratura de lugar comum, ou um livro de autoajuda. Mas, sim, uma maravilhosa fábula que fala sobre o poder criativo da imaginação, destinada aos adultos que perderam a capacidade de ter o pasmo essencial da criança e de se admirar com a eterna novidade do mundo.

Quem sabe mesmo se não nos tornamos impermeáveis, a partir de certa idade, à alegria viçosa e nova, e se as mais doces satisfações do homem maduro podem ser coisa diferente de sentimentos de infância revificados, brisa perfumada que um passado cada vez mais distante nos envia por bafejos cada vez mais raros? (BERGSON, 1983, p. 41).

Nessa citação, Bergson, francês como Exupéry, nascido no entanto, muito antes deste, já havia entendido todas essas coisas, quando foi buscar nas lembranças de nossa infância o sentido profundo da alegria da vida, uma razão ontológica para o riso.

\section{Referências}

ALENDE, Isabel. Contos de Eva Luna. Rio de Janeiro: Bertrand Brasil, 1996.

BACHELARD, Gaston. A poética do espaço. São Paulo:Martins Fontes, 2003.

. O ar e os sonhos: ensaio sobre a imaginação do movimento. São Paulo: Martins Fontes,

1990.

BERGSON, Henri. O riso: ensaio sobre a significação do cômico. Rio de Janeiro: Zahar Editores, 1983.

BONDÍA, Jorge Larrosa. Notas sobre a experiência e o saber de experiência. Conferência proferida no I Seminário Internacional de Educação de Campinas, traduzida por João Wanderley Geraldi e publicada em julho de 2001, por Leituras SME.

CALVINO, Italo. Seis propostas para o próximo milênio. São Paulo: Companhia das Letras, 2004.

FREUD, Sigmund. Sigmund Freud: obras psicológicas, antologia organizada e comentada por Peter Gay. Rio de Janeiro: Imago Editora, 1992.

SAINT-EXUPÈRY, Antoine de. O pequeno príncipe. 42. ed. Rio de Janeiro: Agir, 1994. 